\title{
Central brain herniation in Dandy-Walker syndrome
}

\author{
Suhas Udayakumaran
}

Received: 2 May 2013 / Accepted: 12 June 2013 / Published online: 26 June 2013

(C) Springer-Verlag Berlin Heidelberg 2013

\section{Dear Editor:}

I read the article by Mandiwanza et al. [1] with interest, and I congratulate the authors for publishing the phenomenon. The phenomenon of herniation both upward [4, 7] and downward $[2,3]$ has been documented in case reports.

I would like to add some facts to the physics of the phenomenon of herniation in shunted Dandy-Walker syndrome:

1. Absence of cerebellar peduncular 'restraints' associated with significantly hypoplastic/aplastic 'mobile' vermis and cerebellum favours both upward and downward herniation.

2. Empty 'capacious' posterior fossa facilitates downward herniation.

3. Grossly upward and outwardly displaced tentorium (wide tentoroclival angle) and wide incisura facilitate herniation.

I conclude that a negative pressure gradient between the posterior fossa and supratentorium, secondary to shunt, is an essential component for the phenomenon to generate the respective force vector and its subsequent herniation [6].

The treatment priority at presentation should:

1. Rule out shunt malfunction.

2. In the event of association with clinical over-drainage syndrome, there may be a role for changing the shunt system into a more conservative drainage combination [6] or double and simultaneous shunting en-Y of a lateral ventricle and the posterior fossa cyst [4].
3. When inserting a shunt, the implant of a flow-regulating or an anti-siphon valve should be preferred to differential pressure valves. Low-pressure valves should definitively be avoided [5].

\section{References}

1. Mandiwanza T, Kaliaperumal C, Caird J (2013) Central brain herniation in shunted Dandy walker cyst. Childs Nerv Syst 29(6):10351038

2. Naidich TP, Radkowski MA, McLone DG, Leestma J (1986) Chronic cerebral herniation in shunted Dandy-Walker malformation. Radiology 158:431-434

3. Ng WH, Valiante T (2009) An unusual parahippocampal lesion presenting with seizures. J Clin Neurosci 16:944

4. Pillay P, Barnett GH, Lanzeiri C, Cruse R (1989) Dandy-Walker cyst upward herniation: the role of magnetic resonance imaging and double shunts. Pediatr Neurosci 15:74-78, discussion 78-79

5. Spennato P, Mirone G, Nastro A, Buonocore MC, Ruggiero C, Trischitta V, Aliberti F, Cinalli G (2011) Hydrocephalus in DandyWalker malformation. Childs Nerv Syst 27:1665-1681

6. Udayakumaran S, Ben Sira L, Constantini S (2010) Chronic uncal herniation secondary to posterior fossa shunting: case report and literature review. Childs Nerv Syst 26:267-271

7. Wang AN, Carson BS (1987) Upward herniation of the posterior fossa cyst in the shunted child. Surg Neurol 28:215-220

S. Udayakumaran $(\bowtie)$

Department of Neurosurgery, Division of Paediatric Neurosurgery,

Amrita Institute of Medical Sciences and Research Centre,

Kochi, India

e-mail: dr.suhas@gmail.com 